\title{
EI modelo europeo de cooperación judicial en materia penal tras el Tratado de Lisboa
}

\section{The European model of judicial cooperation in criminal matters after the Treaty of Lisbon}

\author{
Valentina Faggiani \\ Universidad de Granada, España \\ velnf@ugr.es
}

RESUMEN: El presente estudio tiene por objeto el modelo europeo de cooperación judicial en materia penal y sus principales avances. Los objetivos de este sistema de justicia penal son dos: asegurar un estatuto procesal equivalente en los Estados Miembros y elaborar una política criminal común para luchar contra la criminalidad organizada de carácter transfronterizo.

PALABRAS CLAVE: espacio europeo de libertad, seguridad y justicia; lucha contra la criminalidad organizada transfronteriza; reenvío prejudicial; armonización de los derechos procesales, reconocimiento mutuo.

ABSTRACT: This study aims at analyzing the European model of judicial cooperation in criminal matters and its developments. The purposes of this system of criminal justice are two: to guarantee a procedural statute, equivalent in the Member States, and to elaborate a criminal policy to fight against the organized crime of a cross-border nature.

KEY WORDS: the European area of freedom, security and justice; the fight against crossborder organized crimes; preliminary ruling proceeding; the harmonization of procedural law; the mutual recognition. 


\section{SUMARIO}

I. La construcción del ELSJ a través de la cooperación judicial. II. La cooperación intergubernamental como laboratorio para un modelo europeo de justicia penal. III. La evolución de la cooperación judicial en materia penal en la UE: entre intergubernamentalidad y supranacionalidad. IV. El Tratado de Lisboa y la definición de un nuevo Modelo Europeo de Justicia: La competencia de la UE en materia penal. V. El reenvío prejudicial como eje de la cooperación judicial en la UE. VI. Profundización y variabilidad en la Cooperación Judicial: Los frenos de emergencia y la cooperación reforzada. Bibliografía.

\section{La construcción del ELSJ a través de la cooperación judicial}

Para comprender qué es el espacio europeo de libertad, seguridad y justicia (ELSJ) es oportuno partir de la premisa de que la Unión Europea (UE) es un ordenamiento abierto, multinivel, laberíntico, caracterizado por la coexistencia entre una pluralidad de espacios constitucionales. En este espacio común, tras la supresión de los controles a las fronteras internas, las personas, las mercancías, los servicios y los capitales pueden circular libremente. Sin embargo, la afirmación del principio de la libre circulación ha producido, como contrapartida, un incremento exponencial de los supuestos transnacionales, que afectan al ámbito civil y penal. Estos supuestos típicos caracterizados por elementos de extraterritorialidad han impuesto la institución de un modelo europeo de cooperación judicial (civil y penal) y de cooperación policial.

El presente estudio analiza este modelo por sus especificidades y por la importancia que ha adquirido en los últimos años sobre todo tras la entrada en vigor del Tratado de Lisboa ( $1^{\circ}$ de diciembre de 2009). Mediante la puesta en marcha de mecanismos europeos de cooperación judicial se pretende consolidar un sistema de justicia penal común, en el que se garantice un nivel elevado y equivalente de protección de los derechos fundamentales en los Estados miembros (EEMM), y permita a la UE elaborar una política criminal para luchar contra la criminalidad organizada de carácter transfronterizo. 
Es suficiente pensar, por ejemplo, en el terrorismo, el cual se ha convertido en una amenaza constante, el crecimiento de la inmigración ilegal y la trata de seres humanos, que tras la crisis humanitaria de los refugiados está adquiriendo dimensiones incontrolables, las deficiencias de las instituciones judiciales y de los cuerpos de policía y los delitos financieros, que son consecuencia del aumento de las transacciones transfronterizas en una economía cada vez más global. Las estrechas conexiones y recíprocas implicaciones entre estas formas de criminalidad han obligado a los Estados a replantear su estrategia, orientando las políticas represivas-sancionadoras de la UE hacia la elaboración de normas mínimas comunes.

Es por esto que surge la necesidad de instituir instrumentos que permitan eliminar todo obstáculo derivado de la incompatibilidad entre los distintos sistemas judiciales y administrativos. De tal forma, se pretende contribuir al fortalecimiento de una colaboración más estrecha entre las autoridades de los Estados miembros, facilitando la ejecución rápida y simple de las resoluciones judiciales, el acceso a la justicia y la armonización de las legislaciones nacionales, simplificando la comunicación entre los órganos jurisdiccionales de emisión y de ejecución, así como equilibrando el principio de igualdad de armas entre la parte acusadora y la defensa y de contradicción; todos estos principios básicos en el desarrollo de los procesos penales.

\section{La cooperación intergubernamental como laboratorio para un modelo europeo de justicia penal}

El alcance y la importancia de un «modelo europeo de justicia» integrado y basado en la cooperación judicial penal han evolucionado en el tiempo ${ }^{1}$. De hecho, la historia de la UE y la historia de la evolución de su sistema de cooperación judicial van de la mano. En la primera fase del proceso de integración europea, el objetivo principal de los Estados signatarios, de acuerdo con una concepción

1 Sobre los primeros avances de la UE en materia de cooperación judicial penal se reenvía, entre otros, a los siguientes estudios: Chiavario (2005); Bilancia (2004); AdAm (1998). 
funcionalista, era reforzar el «Mercado Interior» mediante la supresión de los controles en las fronteras comunes y el reconocimiento de la libre circulación de personas, mercancías, servicios y capitales.

Atendiendo a este planteamiento, inicialmente los tratados constitutivos no hacían referencia a la existencia de un sistema europeo de cooperación judicial en materia penal. En esta primera fase a los Estados miembros no les interesaba, ni les parecía concebible que una organización supraestatal de carácter meramente económico pudiera asumir competencias en el ámbito penal, sustrayéndolas a los Estados e instituyendo un Derecho penal sin Estado. El Derecho penal representaba el instrumento más autárquico (Bernardi, 2004, p. 2), severo y disuasorio de coacción y control social, cuya titularidad correspondía en forma exclusiva a los Estados nacionales, siendo una prerrogativa inherente al núcleo duro de la soberanía estatal, a la cual éstos no estaban dispuestos a renunciar.

Sin embargo, poco a poco los Estados miembros, gracias también al papel desempeñado en dicho ámbito por el Tribunal de Justicia (TJ) que impulsó el desarrollo de una «cultura judicial europea», empezaron a comprender la necesidad de adoptar un sistema de cooperación judicial en materia penal a fin de hacer de Europa un ELSJ, y dotar de contenido y efectividad a los principios de libertad, democracia, respeto de los derechos fundamentales y del Estado de Derecho.

Además, a partir de la mitad de los años setenta del siglo pasado, comenzaron a desarrollarse las primeras formas de cooperación en materia de justicia y asuntos interiores. Se trataba, en todo caso, de una cooperación informal entre Estados, de naturaleza intergubernamental, externa al marco institucional comunitario, y caracterizada por el método diplomático. Esta primera forma de cooperación judicial se desarrollaba en términos de coordinación entre Estados para el estudio de materias, como el terrorismo o la inmigración, que afectaban a intereses considerados de particular relevancia para los Estados. A tal efecto, se procedió a la institución de grupos de trabajo de carácter intergubernamental con la función de examinar sectores parciales de la libre circulación de las personas, 
como el Grupo de Trabajo Trevi, instituido en diciembre de 1975 a propuesta inglesa.

El modelo de cooperación intergubernamental, a pesar de sus evidentes carencias, como la falta de transparencia en los procesos decisorios, el consiguiente déficit democrático y la ausencia de un control jurisdiccional, representa la primera etapa del largo camino hacia la construcción de un ELSJ sin fronteras en el que los derechos procesales básicos de las personas sean no solo reconocidos sino también efectivamente tutelados.

Precisamente en dicho contexto se advirtió la necesidad de establecer un modelo de cooperación judicial europeo, encontrando su primera concreción en el Convenio de Schengen (adoptado el 14 de junio de 1985). Los Estados signatarios del Acervo de Schengen, de acuerdo con la teoría funcionalista, pretendían «potenciar», a través de la institución del Mercado Interior, la integración europea y hacer posible que Europa se convirtiera con más rapidez en un ELSJ, en el que se lograra «la supresión de controles en las fronteras comunes y la circulación de personas» y se facilitara el «transporte y la circulación de mercancías».

El Convenio de Schengen recoge en los Títulos III y IV medidas de asistencia judicial en materia penal, regula el principio ne bis in idem, la extradición, la transmisión de la ejecución de sentencias penales y procede a la institución del sistema de información de Schengen. De esta forma, la Comunidad Europea vinculaba el desarrollo económico, la prosperidad y el bienestar de sus Estados miembros a la configuración de un ELSJ, en el que se incardina un sistema europeo de cooperación judicial capaz de asegurar la tutela judicial efectiva de los derechos y libertades, a través del establecimiento progresivo de un marco mínimo común.

En esta línea, el 28 de febrero de 1986 se adoptó el Acta Única Europea, que con vistas a la construcción del «mercado interior» y a la promoción de la libre circulación de las personas procedió a la institucionalización de la cooperación política europea entre los Estados Partes. El Acta Única dio el impulso necesario 
para acelerar la adopción del Convenio de Aplicación del Acuerdo de Schengen (firmado el 19 de junio de 1990 y en vigor desde el 26 de marzo de 1995), el cual fue integrado al Derecho de la Unión Europea por el Tratado de Ámsterdam en 1997. Este Convenio, de naturaleza programática, establece una serie de prioridades y medidas a medio y a largo plazo para la elaboración de un sistema de cooperación permanente y judicial.

Por todo lo hasta aquí referido, esta primera etapa del proceso de construcción del ELSJ, a pesar de las imperfecciones, puede ser valorada positivamente: el Acuerdo de Schengen y su Convenio de Aplicación se pueden concebir como un laboratorio, que ha determinado la institución posterior de un modelo de justicia europeo integrado. La supresión de las fronteras es funcional al desarrollo del sentido de pertenencia a la Comunidad. Los ciudadanos de los Estados miembros y los extranjeros legalmente residentes en dicho espacio deben poder circular, beneficiando de una adecuada tutela y de una protección judicial uniforme, gracias a la definición de un marco mínimo común y a un grado más elevado de coordinación y de integración entre los aparatos de control y judiciales de los Estados. Las fronteras dividen, separan, crean intolerancias. Afortunadamente, los Estados han asumido que el desarrollo de una política económica común depende también de un sistema europeo de justicia, que funcione correcta y eficazmente y en el que se hayan eliminado todos los obstáculos a los procedimientos judiciales transfronterizos.

\section{La evolución del modelo europeo de cooperación judicial en materia penal en la UE: entre intergubernamentalidad y supranacionalidad}

Sin embargo la construcción de un modelo europeo de cooperación judicial en materia penal tuvo un impulso decisivo con la adopción del Tratado de Maastricht (firmado el 7 de febrero de 1992 y en vigor desde el $1^{\circ}$ de noviembre de 1993), el cual marcó el comienzo de una nueva fase en este proceso. Dicho Tratado procedió a la institución de la Unión Europea (UE) y al reconocimiento del 
concepto de ciudadanía europea y del respeto de los derechos fundamentales, considerados principios generales del Derecho comunitario (art. F, apartado 2, TUE). El Tratado de la Unión Europea (TUE) institucionalizó en el Título VI, bajo la denominación «Disposiciones relativas a la cooperación en los ámbitos de Justicia y Asuntos de Interior», la cooperación judicial en materia penal y la cooperación policial (art. K 1, apartados 7 y 9), considerándolas entre las materias de «interés común» para la realización de los fines de la Unión y en particular de la libre circulación de personas.

De tal forma, se sentaron las líneas fundamentales de la arquitectura en pilares ${ }^{2}$, que permanecerá hasta la entrada en vigor del Tratado de Lisboa. Además, se legitimó al Consejo a adoptar actos normativos, como las acciones y las posiciones comunes (que el Tratado de Ámsterdam denominará «decisiones marco»), y a celebrar convenios en los que se podía disponer que el TJ fuera competente para interpretar las disposiciones de los mismos y dictar sentencias en los litigios relativos a su aplicación. Así se otorgaba al tercer pilar un matiz comunitario y ya no meramente intergubernamental, que lo enmarcaba en el proyecto de construcción europea, transformándolo progresivamente en una realidad supranacional.

La etapa siguiente en este proceso es representada por el Tratado de Ámsterdam, firmado el 2 de octubre de 1997, en el cual, por primera vez, se adoptó el concepto de «espacio de libertad, seguridad y justicia» y se procedió a la incorporación al marco de la UE del Acquis de Schengen. De esta manera, se impulsó la definitiva comunitarización de las materias relativas a la libre circulación de las personas: visados, asilo, inmigración y fronteras, que pasaron

2 Vid. Alonso García (2007: 344). Como afirma el autor, la «identificación del segundo y del tercer pilar de la Unión como "intergubernamentales", sin más, que tuvo su razón de ser con el Tratado de Maastricht, resultó ya matizada por el Tratado de Ámsterdam, que implicó una doble comunitarización del tercer pilar, por aquel entonces dedicado a la "cooperación en los ámbitos de la justicia y de los asuntos de interior». Todo ello determinaría por un lado una comunicación consistente en el traspaso de parte del tercer pilar, el concerniente a visados, inmigración, asilo, control de fronteras externas e internas, y cooperación judicial en temas civiles, al Tratado de la Comunidad Europea; y por otro, aires de comunitarización, en grado sensiblemente inferior a la operación anterior, consistente en la introducción de algunos rasgos próximos al régimen comunitario en la parte del tercer pilar que allí permaneció como cooperación judicial y policial en materia penal». 
del tercer al primer pilar comunitario, convirtiendo la cooperación judicial en materia civil en una política sistemática de la UE.

Además, en dicho Tratado, la cooperación judicial en materia penal, regulada en el Título VI, se concibió de un ámbito de interés común a uno de los principales retos de la UE, al disponer que: «Sin perjuicio de las competencias de la Comunidad Europea, el objetivo de la Unión será ofrecer a los ciudadanos un alto grado de seguridad dentro de un espacio de libertad, seguridad y justicia elaborando una acción en común entre los Estados miembros en los ámbitos de la cooperación policial y judicial en materia penal», que incluirá, entre otras medidas: «una mayor cooperación entre las autoridades judiciales y otras autoridades competentes de los Estados miembros» y «la aproximación, cuando proceda, de las normas de los Estados miembros en materia penal de conformidad con lo dispuesto en la letra e) del artículo 31» (art. 29). Este último legitimaba a la UE para adoptar progresivamente «medidas que establezcan normas mínimas», bajo la forma de decisiones marco, «relativas a los elementos constitutivos de los delitos y a las penas en los ámbitos de la delincuencia organizada, el terrorismo y el tráfico ilícito de drogas».

Sin embargo, aunque parte de la doctrina empezó a considerar las decisiones marco la base jurídica suficiente para que la Unión pudiera legislar en el ámbito penal, dicha fuente planteaba no pocos problemas puesto que se trataba de actos normativos sin eficacia directa, que requerían para su adopción la unanimidad del Consejo, al cual correspondía la dirección estratégica y el fomento de la cooperación. Era opinión consolidada que las disposiciones de una decisión marco que no habían sido incorporadas o habían sido incorporadas incorrectamente al Derecho interno no podían ser aplicadas directamente por el juez nacional, puesto que tales actos no tenían efectos directos. Esta teoría fue modificada tras la histórica sentencia del TJ del 16 de junio de 2005, pronunciada en el asunto Pupino, C-105/03, relativa a la Decisión marco del Consejo del 15 de marzo de 2001 sobre el estatuto de la víctima en el proceso penal ${ }^{3}$, en la que, afirmando el principio de la interpretación conforme, se reconoció implícitamente

3 Diario Oficial, L 082, 22.3.2001. 
que también las decisiones marco pueden tener efectos directos.

Por todo ello, de acuerdo con Alonso García, «Ámsterdam habría convertido» el pilar «concerniente a la cooperación policial y judicial en materia penal en un tertium genus, de carácter fuertemente intergubernamental, pero con presencia, al mismo tiempo, de rasgos supranacionales en los instrumentos de intervención y en los mecanismos de control judicial» (Alonso, 2007, p. 345), sentando las bases jurídicas para el progresivo desarrollo de un espacio judicial de naturaleza penal y alcance europeo armonizado.

Poco después de la adopción del Tratado de Ámsterdam, se celebró el Consejo extraordinario de Tampere (15 y 16 de octubre de 1999)4 hecho que constituyó un momento muy importante, de fuerte implicación y compromiso político. En Tampere empezó a desarrollarse y llenarse de contenido el concepto de espacio judicial europeo, siendo uno de sus logros principales. A tal fin, los Estados de la Unión traspusieron al ámbito de la cooperación judicial penal la «fórmula mágica» del principio de reconocimiento mutuo de las sentencias y de las otras resoluciones judiciales, «la piedra angular de la cooperación judicial» en la Unión, tanto en materia civil como penal. ${ }^{5}$

El reconocimiento mutuo se asienta sobre un fundamento: la reciproca confianza entre los Estados miembros en cuanto a que, sin perjuicio de la mayor o menor conveniencia de aproximar los sistemas punitivos nacionales, en su doble dimensión sustantiva y procesal, las diversas normativas internas relativas al conjunto de garantías y recursos jurisdiccionales a los que el individuo puede acudir deben ser consideradas equivalentes de cara a satisfacer los preeminentes valores e intereses jurídicos en juego. De tal forma, se pone de relieve la necesidad de adoptar normas mínimas, ${ }^{6}$ que garanticen un nivel adecuado de asistencia jurídica, así como normas especiales de procedimiento comunes para la tramitación simplificada y acelerada de los litigios transfronterizos en toda la Unión.

4 Programa de Tampere: Hacia una Unión de libertad, seguridad y justicia, Conclusiones de la Presidencia, Consejo Europeo de Tampere de 15 y 16 de octubre de 1999.

5 Conclusiones de la Presidencia, Consejo Europeo de Tampere de 15 y 16 de octubre de 1999, apartado 33.

6 Ibídem, apartado 37. 
Tales principios fueron reiterados tanto en el Programa de medidas (del Consejo y de la Comisión) destinado a poner en práctica el reconocimiento mutuo de las resoluciones en materia penal (2001), ${ }^{7}$ así como en el Programa de la Haya. ${ }^{8}$ Poco después, en dicho marco, se adoptó la Decisión Marco del Consejo del 13 de junio de 2002 relativa a la orden de detención europea y a los procedimientos de entrega entre Estados miembros, ${ }^{9}$ que es el primer y el más emblemático instrumento de concreción y aplicación del principio de reconocimiento mutuo.

Por su parte, en dicho contexto no se puede soslayar la importancia del Tratado Constitucional, ${ }^{10}$ que si bien tras los referéndums de Francia y Holanda (2005) no pudo entrar en vigor, preveía algunas disposiciones destinadas a incidir en el espacio europeo de justicia penal. Éstas por su importancia fueron posteriormente incorporadas, como se verá, al Tratado de Lisboa. ${ }^{11}$ Por todo ello, a pesar de su no entrada en vigor, el Tratado Constitucional representa la manifestación de la toma de conciencia por parte de los Estados de la UE de la necesidad de «comunitarizar» el tercer pilar, dotando al sistema europeo de cooperación judicial en materia penal y policial de bases jurídicas más sólidas y de una estrategia de acción conjunta para la adopción de mecanismos y estándares mínimos uniformes de protección de los derechos fundamentales del justiciable.

Los Estados de la Unión se habían concienciado finalmente de que el grado de desarrollo de la cooperación judicial en materia penal no había alcanzado

7 DO C n. 12 15.01.2001.

8 DOC: $53,03.03 .2005$.

9 DO L 190, 18.07.2002.

$10 \mathrm{Al}$ respecto, vid. Bernardi, (2004); De Miguel Zaragoza (2004); Gómez-Jara Díez (2004).

11 Entre los aspectos más relevantes en materia de protección de los derechos fundamentales, que el Tratado por el que establece una Constitución para Europa contenía, es preciso mencionar la incorporación de la Carta, que en el Título VI dedicado a la Justicia reconocía el derecho a la tutela judicial efectiva y a un juez imparcial (art. II-107), la presunción de inocencia y los derechos de la defensa (art. II-108), la supresión de la estructura en pilares con la consiguiente comunitarización del tercer pilar relativo a la cooperación en materia penal (v. art. III-257 y la Sección IV relativa a la cooperación en materia penal, en particular el art. III 270), que legitimaba a la UE a establecer normas mínimas comunes sobre los derechos de las personas en el proceso penal, la institucionalización del principio de reconocimiento mutuo en el ámbito penal y la extensión de la competencia del TJUE para resolver en vía prejudicial las cuestiones que afectan al ELSJ en su conjunto (Subsección V, art. 369).

\section{DERECHO GLOBAL. ESTUDIOS SOBRE DERECHO Y JUSTICIA}


las expectativas, quedándose en un nivel bastante bajo por los bloqueos políticos, los retrasos y por el escepticismo que ha caracterizado el desarrollo de este ámbito. En este sentido, la protección de los derechos a un juicio imparcial como la presunción de inocencia, el derecho de defensa, los derechos de las víctimas de delitos, el ne bis in idem y las salvaguardias procesales mínimas en el supuesto de la detención preventiva, sobre todo en los procesos penales, son fundamentales para que Europa siga en el proceso de integración y constitucionalización. ${ }^{12}$

\section{EI Tratado de Lisboa y la definición de un nuevo «Modelo Europeo de Justicia»: La competencia de la UE en materia penal}

Finalmente, en la tercera fase del proceso de integración europea, y de forma especial tras la entrada en vigor del Tratado de Lisboa, la UE adquirió conciencia de la necesidad de consolidar una «cultura penal europea», en virtud de la existencia de principios generales compartidos, fruto de las tradiciones constitucionales comunes a los Estados miembros, y de la centralidad de los derechos fundamentales que la UE confiere a los particulares. De esta forma, se manifiesta expresamente su intención de dotarse de un propio modelo de justicia penal. Este constituye el elemento clave y determinante para avanzar en el proceso de integración y de constitucionalización.

El Tratado de Lisboa, mediante la supresión formal de los pilares comunitarios, rediseña la estructura arquitectónica de la Unión. ${ }^{13}$ La «comunitarización» del tercer pilar y la «nueva» definición del ESLJ, que es antepuesto incluso al Mercado Interior, ${ }^{14}$ han tenido consecuencias importantes

12 Recomendación del Parlamento Europeo, de 7 de mayo de 2009, destinada al Consejo sobre el desarrollo de un espacio de justicia penal en la UE (2009/2012(INI). Sobre el punto se reenvía al considerando F.

13 Se habla de supresión formal de los tres pilares porque la PESC sigue estando caracterizada por elementos eminentemente intergubernamentales; en cambio la cooperación judicial en materia penal se ha convertido a todos los efectos en Derecho de la UE.

14 En confirmación de todo esto, el art. 3 TUE dispone que la Unión ofrecerá a sus ciudadanos «un espacio de libertad, seguridad y justicia, sin fronteras interiores, en el que esté garantizada la libre circulación de personas, 
en el proceso de integración europea. Se trata de cambios que han afectado a las competencias, a los procesos decisorios y a los mecanismos de protección de los derechos fundamentales.

Ante todo, la extensión a dicho ámbito del «método comunitario» ha puesto fin a la denominada «batalla entre los pilares», ${ }^{15}$ atribuyendo una competencia expresa a la UE en materia penal (sustantiva y procesal). Ahora el procedimiento legislativo ordinario es llevado a cabo por el Parlamento y el Consejo y el Tribunal de Justicia de la Unión Europea (TJUE) puede pronunciarse en vía prejudicial con carácter general y obligatorio sobre las materias relativas al ELSJ en su conjunto. Esto refuerza no solo la cooperación y el diálogo entre este último y los jueces nacionales, sino que contribuye a la construcción de un verdadero espacio judicial europeo que ya no se rige por las lógicas y los mecanismos meramente intergubernamentales. Además, no se puede soslayar la constitucionalización del principio de reconocimiento mutuo (art. 82 TFUE).

El Título V del TFUE confirma la íntima interrelación entre cooperación judicial y ELSJ ${ }^{16}$. Los dos pilares en torno a los que se desarrolla dicho espacio son la aproximación entre las legislaciones penales de los Estados miembros y la cooperación judicial (horizontal y vertical). En lo que concierne a la aproximación de las legislaciones los artículos 82 y 83 del TFUE dotan a la UE de una «base jurídica explícita», que la legítima, acudiendo al procedimiento legislativo ordinario, para adoptar normas mínimas comunes en materia penal, procesal y sustantiva respectivamente, bajo la forma de directivas.

junto con medidas adecuadas en materia de control de las fronteras exteriores, asilo, inmigración, de prevención y lucha contra la delincuencia» a fin de asegurar un nivel elevado de seguridad.

15 Sobre la «batalla entre los pilares»: Condinanzi (2007); Munari y Amalfitano (2007); SÁnchez Legido (2007); WASMEIER y ThWAITES (2004).

16 El Título V del TFUE se estructura en los siguientes capítulos: Capítulo 1: Disposiciones generales (arts. 67-76 TFUE); Capítulo 2: Políticas sobre controles en las fronteras, asilo e inmigración (arts. 77-80 TFUE); Capítulo 3: Cooperación judicial en materia civil (art. 81 TFUE); Capítulo 4: Cooperación judicial en materia penal (arts. 82-86 TFUE); Capítulo 5: Cooperación policial (87-89 TFUE). Sobre el «modelo europeo de cooperación judicial en materia penal tras el Tratado de Lisboa», vid.: De Hoyos SAncho (2018); Kostoris (a cura di) (2017); Montaldo (2015), Arangüena Fanego, C. (coord.) (2011); García Rivas, N. (2010); Jimeno Bulnes, M. (2010); Aprile y Spiezia (2009); Calderón Cuadrado y Iglesias Buhigues (2009); Lirola Delgado, I. (2008). 
El reparto de competencias establecido no pone en discusión el papel de los Estados miembros, los cuales siguen ostentando la competencia en dicho ámbito, aunque admiten que su potestad decisoria pueda ser constitucionalmente delimitada cuando sea necesario para contribuir a mejorar los sistemas de justicia nacionales y la cooperación entre ellos en el marco de un sistema judicial integrado. Se trata de competencias compartidas entre la UE y los Estados miembros, basadas en los principios de atribución, proporcionalidad y subsidiariedad. En este sentido, se reconoce que la construcción de un espacio de justicia penal, por la importancia, la complejidad y el carácter constitucionalmente sensible de los objetivos a perseguir y de los intereses en juego, requiere de una intervención desde el nivel de la UE. ${ }^{17}$

En lo que concierne al ámbito procesal penal, el art. 82.1 del TFUE, que regula el establecimiento de disposiciones mínimas para su armonización, prevé que «La cooperación judicial en materia penal en la Unión se basará en el principio de reconocimiento mutuo de las sentencias y resoluciones judiciales e incluye la aproximación de las disposiciones legales y reglamentarias de los Estados miembros» en asuntos penales con dimensión transfronteriza.

A tal fin, el Parlamento Europeo y el Consejo pueden adoptar, con arreglo al procedimiento legislativo ordinario, medidas que tienden a:

a) establecer normas y procedimientos para garantizar el reconocimiento en toda la Unión de las sentencias y resoluciones judiciales en todas sus formas;

b) prevenir y resolver los conflictos de jurisdicción entre los Estados miembros;

c) apoyar la formación de magistrados y del personal al servicio de la administración de justicia;

17 Según el art. 5.3 TUE: «En virtud del principio de subsidiariedad, en los ámbitos que no sean de su competencia exclusiva, la Unión intervendrá solo en caso de que, y en la medida en que, los objetivos de la acción pretendida no puedan ser alcanzados de manera suficiente por los Estados miembros, ni a nivel central ni a nivel regional y local, sino que puedan alcanzarse mejor, debido a la dimensión o a los efectos de la acción pretendida, a escala de la Unión». 
d) facilitar la cooperación entre las autoridades judiciales o equivalentes de los Estados miembros en el marco del procedimiento penal y de la ejecución de resoluciones.

De la lectura de esta disposición se deduce que el principio del reconocimiento mutuo de las sentencias y resoluciones judiciales y la aproximación de las legislaciones penales, materiales y procesales, en el marco de la cooperación policial y judicial en asuntos penales con dimensión transfronteriza, actúan en dos niveles distintos, puesto que la aplicación efectiva del primero parece depender de la existencia de un cierto grado de armonización de las legislaciones penales.

Por lo tanto, en virtud del reconocimiento mutuo las sentencias y las resoluciones judiciales de carácter penal, adoptadas por cualquier órgano jurisdiccional de los Estados miembros, serán reconocidas automáticamente, adquiriendo validez y eficacia en todo el territorio de la UE. Sobre la base de la existencia de la confianza recíproca y de un conjunto de valores e ideales comunes, los Estados Miembros deberán aceptar el contenido de las resoluciones dictadas por los demás sin necesidad de someterlas a un control previo, por ejemplo, respecto de la doble incriminación del supuesto delictivo. Pero precisamente para evitar problemas de legitimidad constitucional, como había ocurrido en el caso de la orden de detención europea (ODE), el reconocimiento mutuo requiere la armonización previa de las legislaciones penales a través de la adopción de un marco mínimo común.

A continuación, en el segundo apartado, el art. 82 del TFUE indica algunos de los ámbitos de carácter estrictamente procesal en los que el Parlamento Europeo y el Consejo podrán establecer normas mínimas mediante directivas. Estas directivas de mínimos, que son adoptadas con arreglo al procedimiento legislativo ordinario, cuando se estime necesario para facilitar el reconocimiento mutuo de las sentencias y resoluciones judiciales y la cooperación policial y judicial en asuntos penales con dimensión transfronteriza, deberán tener en cuenta «las diferencias entre las tradiciones y los sistemas jurídicos de los Estados 
miembros».. ${ }^{18}$

Dichas normas se refieren a lo siguiente:

a) Admisibilidad mutua de pruebas entre los Estados miembros;

b) Derechos de las personas durante el procedimiento penal;

c) Derechos de las víctimas de los delitos;

d) Otros elementos específicos del procedimiento penal, que el Consejo habrá determinado previamente mediante una decisión. En este último supuesto, el Consejo se pronunciará por unanimidad, previa aprobación del Parlamento Europeo. Este último inciso constituye una excepción a la regla del procedimiento legislativo ordinario, basado en la codecisión entre Parlamento y Consejo.

En cambio, con respecto al Derecho penal de carácter sustantivo, el art. 83.1 TFUE legitima a la UE para establecer mediante directivas (adoptadas por el Parlamento y el Consejo con arreglo al procedimiento legislativo ordinario) normas mínimas que institucionalicen los supuestos típicos delictivos y las sanciones correlativas en ámbitos específicos, que sean de «especial gravedad», como el terrorismo, la trata de seres humanos y la explotación sexual de mujeres y niños, y tengan una «dimensión transfronteriza», esto es, que afecte a dos o más Estados y derive directamente del «carácter o de las repercusiones de dichas infracciones o de una necesidad particular de combatirlas según criterios comunes».

De todas formas, en ambos casos se trata de una competencia «expresa» porque es reconocida y formalizada en el Tratado de Lisboa, con arreglo a la cual se legitima a la UE para actuar en materia penal dentro de los límites de las competencias que le atribuyen los Estados miembros. De lo contrario, por el

18 En cambio, en el supuesto de la aproximación sustantiva ex art. 83 TFUE no se hace referencia expresa al respeto de las distintas tradiciones y sistemas jurídicos de los Estados Miembros aunque es evidente que no se podrá prescindir de la necesidad de individualizar un marco mínimo común respecto de los supuestos típicos delictivos, de las sanciones correspondientes y de las categorías penales principales, teniendo debidamente en cuenta también las diferencias más importantes entre los sistemas judiciales y las tradiciones penales de los Estados Miembros. 
principio de atribución, hubiera quedado reservada a los Estados miembros (art. 4 TUE).

La atribución de una competencia a la UE en materia penal, sustantiva y procesal, determina un desplazamiento de la responsabilidad en la garantía de los derechos en lo que concierne al ejercicio de la potestad sancionadora, tradicionalmente ejercida por parte de los Estados hacia la UE. Por consiguiente, los Estados deberán conformarse a los principios generales de esta Comunidad de Derecho ${ }^{19}$. En este sentido, el proceso de adaptación de los Estados a los principios y estándares establecidos en materia de justicia por la UE constituye la señal más tangible de su constitucionalización.

La competencia de la UE se lleva a cabo mediante el instrumento de las directivas, que se convierten en la fuente para la armonización del Derecho penal, sustituyendo las decisiones marco. Estos actos normativos crean una obligación de resultado hacia los Estados para la adopción de una determinada política criminal, aunque les deja un cierto margen de actuación en lo que concierne a la forma y a los medios mediante los que alcanzar tales objetivos.

Las directivas europeas establecen, por lo tanto, una obligación de tutela para los Estados miembros. Los legisladores nacionales tendrán que activarse para transponer e incorporar tales actos normativos a sus ordenamientos internos y los jueces tendrán que interpretarlos atendiendo al principio de la interpretación conforme (Bernardi, 2013). Y aunque los Estados sigan manteniendo el monopolio del ius puniendi, correspondiéndoles en vía exclusiva la potestad de juzgar y hacer ejecutar lo juzgado, todo ello ha supuesto un replanteamiento y una reordenación de la soberanía estatal hacia un fin común.

No obstante, las decisiones marcos del ex tercer pilar siguen vigentes, dando vida a un fenómeno de ultractividad. Además, tras la finalización, el $1^{\circ}$ de diciembre de 2014, del régimen transitorio quinquenal previsto en el art. 9 del Protocolo n. 36, la Comisión y el TJUE han adquirido las mismas atribuciones

19 En tal sentido, se remite a las Conclusiones del Abogado General del TJUE, P. Cruz Villalón, presentadas el 12 de junio de 2012, Aklagaren/Hans Ákerberg Fransson, C-617/10, apartado 51. 
sobre los actos del ex tercer pilar que sobre aquellos de cooperación judicial penal post-Lisboa.

La producción normativa de la UE en los últimos años ha sido intensa. La primera directiva en materia penal ex art. 83 TFUE ha sido la Directiva 2011/36/UE de 5 abril de 2011 relativa a la prevención y lucha contra la trata de seres humanos y a la protección de las víctimas ${ }^{20}$, en la que se han establecido normas mínimas para armonizar el «tipo» y la «intensidad» de las sanciones ante la comisión de infracciones relacionadas con la trata de seres humanos. Esta medida ha impulsado la adopción de una serie de medidas en el ámbito penal sustantivo. Pero sobre todo, no podemos soslayar los dos paquetes de directivas sobre derechos procesales aprobados por la UE atendiendo al art. $82 \mathrm{TFUE}^{21}$.

La adopción, aunque a pequeños pasos, de tales medidas representa la señal de que la UE se ha dado finalmente cuenta de la necesidad y de la oportunidad de llevar a cabo una acción legislativa desde un nivel de tutela supranacional, trascendente a los ordenamientos jurídicos nacionales en tiempos rápidos, mediante el desarrollo de mecanismos de cooperación judicial eficientes, el refuerzo del reconocimiento mutuo de las sentencias y resoluciones judiciales y la aproximación de las legislaciones en el ámbito europeo; elementos estos que tras la entrada en vigor del Tratado de Lisboa han adquirido un valor «materialmente constitucional».

20 DOUE L 101/1, 15.4.2011.

21 Integran el primer paquete: la Directiva 2010/64/UE sobre el derecho a la interpretación y traducción en los procesos penales en la Unión Europea, de 20 de octubre de 2010, DOUE L 280/1, 26.10.2010; la Directiva 2012/13/UE relativa al derecho a la información en los procesos penales, de 22 de mayo de 2012, DOUE L 142/1, 1.6.2012; y la Directiva 2013/48/UE sobre el derecho de acceso a un abogado en los procesos penales y el derecho de comunicación en el momento de la detención, de 22 de octubre de 2013, DOUE L 294/1, 6.11.2013. Y el segundo está integrado por otras tres medidas: la Directiva 2016/343 por la que se refuerzan en el proceso penal determinados aspectos de la presunción de inocencia y el derecho a estar presente en el juicio, de 9 de marzo de 2016, DOUE L 65/1, 11.3.2016; la Directiva 2016/800/UE relativa a las garantías procesales de los menores sospechosos o acusados en los procesos penales de 11 de mayo de 2016, DOUE L 132/1, 21.5.2016, y la Directiva (UE) 2016/1919 del Parlamento Europeo y del Consejo de 26 de octubre de 2016 relativa a la asistencia jurídica gratuita a los sospechosos y acusados en los procesos penales y a las personas buscadas en virtud de un procedimiento de orden europea de detención, DOUE L 297/1, 4.11.2016. Sobre estos dos paquetes, vid.: Arangüena Fanego, C. y de Hoyos Sancho, M. (dirs.) y Begoña Vidal Fernández, B. (coord.) (2018); Arangüena Fanego (2016); ID (2017); FagGiani (2017 a); ID. (2017b). 


\section{El reenvío prejudicial como eje de la cooperación judicial en la UE}

El Tratado de Lisboa amplía también las competencias y el margen de incidencia del Tribunal de Justicia de la UE en el ELSJ ${ }^{22}$. Por un lado, en lo que concierne a su ámbito de competencia material, el TJUE ha adquirido la competencia para pronunciarse en vía prejudicial ${ }^{23}$ sobre el conjunto de las cuestiones que afectan al ELSJ, entre otros, los visados, la regulación del asilo, la inmigración y las otras políticas relacionadas con la libre circulación de personas, el estatuto del inmigrante, el reconocimiento y la ejecución de sentencias, la criminalidad transfronteriza y en general todo el conjunto de medidas que integran la cooperación judicial, tanto civil como penal ${ }^{24}$.

Y por otro, en lo que concierne a la legitimación para plantear un reenvío prejudicial sobre un asunto que afecte a la cooperación judicial en materia penal, dicha competencia ya no está condicionada como antes de la entrada en vigor del Tratado de Lisboa a una declaración de cada Estado miembro en la que se procedía a su reconocimiento y se indicaban los órganos jurisdiccionales nacionales habilitados para someterle el asunto, sino que ha adquirido un valor

22 El TJUE tiene básicamente las siguientes funciones: a) garantizar la uniforme aplicación e interpretación del Derecho de la UE por los Estados miembros; b) asegurar que los Países miembros y las instituciones europeas cumplan la legislación de la UE; c) proteger los derechos fundamentales en el ámbito de aplicación del Derecho de la UE.

23 El reenvío prejudicial está regulado en el art. 267 TFUE (antiguo artículo 234 TCE), según el cual: «El Tribunal de Justicia de la Unión Europea será competente para pronunciarse, con carácter prejudicial: a) sobre la interpretación de los Tratados; b) sobre la validez e interpretación de los actos adoptados por las instituciones, órganos u organismos de la Unión; Cuando se plantee una cuestión de esta naturaleza ante un órgano jurisdiccional de uno de los Estados miembros, dicho órgano podrá pedir al Tribunal que se pronuncie sobre la misma, si estima necesaria una decisión al respecto para poder emitir su fallo. Cuando se plantee una cuestión de este tipo en un asunto pendiente ante un órgano jurisdiccional nacional, cuyas decisiones no sean susceptibles de ulterior recurso judicial de Derecho interno, dicho órgano estará obligado a someter la cuestión al Tribunal. Cuando se plantee una cuestión de este tipo en un asunto pendiente ante un órgano jurisdiccional nacional en relación con una persona privada de libertad, el Tribunal de Justicia de la Unión Europea se pronunciará con la mayor brevedad».

24 La referida extensión del ámbito material de competencia del TJUE ha sido posible, a través de la derogación de los arts. 35 TUE y 68 TCE, que establecían restricciones a la jurisdicción del TJUE en el ámbito de la cooperación judicial penal. 
automático y generalizado, salvo que los Tratados dispongan otra $\cos a^{25}$.

Además, junto a la extensión del mecanismo del reenvío prejudicial al Espacio europeo de justicia penal, se prevé la posibilidad de plantear al TJUE una cuestión prejudicial de urgencia para las cuestiones inherentes al ELSJ, cuando la persona implicada en el procedimiento se encuentre privada de la libertad ${ }^{26}$. Por lo tanto, mediante la «comunitarización» del tercer pilar, se ha reforzado el papel del reenvío prejudicial como el principal instrumento de cooperación leal y de «diálogo de jueces y entre jueces», de garantía de la coexistencia de los diferentes instrumentos de protección de los derechos fundamentales. Además, se ha convertido al TJUE en una de las principales fuentes de armonización de los derechos y de las garantías procesales en la Unión Europea, puesto que ahora todos los órganos jurisdiccionales nacionales y no solo los órganos jurisdiccionales superiores de última instancia (en este caso se configura como una obligación) pueden interponer un reenvío prejudicial, cuando se les plantee una duda sobre la interpretación de los Tratados y la validez e interpretación de los actos adoptados por las instituciones, órganos u organismos de la Unión en el marco del ELSJ, si lo consideran necesario para resolver el supuesto del que estén conociendo (art. 267 TFUE).

De tal forma, mediante el mecanismo del reenvío prejudicial, que constituye el «eje de la arquitectura judicial de la UE» (SARMiENTo RAmírez EsCUDERO, 2004: pp. 50 y ss), el TJUE puede desarrollar a todos los efectos una

25 Los artículos 275 y 276 TFUE establecen una excepción a la posibilidad de plantear el reenvío prejudicial. El primero excluye del ámbito material de dicho recurso las disposiciones relativas a la política exterior y de seguridad común y los actos adoptados sobre la base de éstas, aunque afirma que «No obstante, el Tribunal de Justicia será competente para controlar el respeto del artículo 40 del Tratado de la Unión Europea y para pronunciarse sobre los recursos interpuestos en las condiciones contempladas en el párrafo cuarto del artículo 263 del presente Tratado y relativos al control de la legalidad de las decisiones adoptadas por el Consejo en virtud del capítulo 2 del título V del Tratado de la Unión Europea por las que se establezcan medidas restrictivas frente a personas físicas o jurídicas». Y el segundo prevé que el TJUE «[...] no será competente para comprobar la validez o proporcionalidad de operaciones efectuadas por la policía u otros servicios con funciones coercitivas de un Estado miembro, ni para pronunciarse sobre el ejercicio de las responsabilidades que incumben a los Estados miembros respecto del mantenimiento del orden público y de la salvaguardia de la seguridad interior».

26 Al respecto, vid. el art. 23 bis del Protocolo n. 3 sobre el Estatuto del Tribunal de Justicia de la Unión Europea y el art. 104 ter del Reglamento de Procedimiento del Tribunal de Justicia. 
función integradora, tanto de carácter «negativo» o de control de conformidad de los derechos procesales nacionales al Derecho de la UE, como de carácter «positivo», «materialmente constitucional», de «armonización»y «unificación» de los derechos procesales nacionales, incentivando y reforzando el diálogo judicial entre los órganos jurisdiccionales europeos, tanto en su fase ascendente como descendente. Es por todo ello que se puede afirmar que el $\mathrm{TJ}$ se ha convertido en el motor también del Espacio Europeo de Justicia Penal.

En este proceso circular el punto de referencia constante son los ordenamientos jurídicos de los Estados miembros de la UE, los cuales acaban pasando necesariamente por el filtro de los principios generales, de aquel «acquis» elaborado por el TJ a partir de la recepción e interiorización de las tradiciones constitucionales comunes a los Estados miembros. La importancia del nuevo papel asumido en el ámbito penal por el Tribunal de Justicia ha sido confirmada por las «sentencias gemelas», Melloni y Fransson" ${ }^{27}$, ambas pronunciadas el 26 de febrero de 2013, y más recientemente por las sentencias Taricco I y Taricco $\mathrm{II}^{28}$. Tales pronunciamientos han impulsado el desarrollo de un nuevo marco de protección de los derechos fundamentales del justiciable, que será objeto sin duda de interesantes evoluciones.

Además, a partir del $1^{\circ}$ de diciembre de 2014, tras la desaparición de la limitación temporal contenida en el art. 10, apartado 1, del Protocolo n. 36, el TJUE ha adquirido una competencia plena en las materias concernientes al ELSJ, pudiendo pronunciarse también sobre las medidas adoptadas en el marco del antiguo tercer pilar, sin las limitaciones que lo caracterizaban ${ }^{29}$.

En lo que concierne al estatus especial del que gozan determinados Estados, es

27 TJUE, sentencia de 26 de febrero de 2013, Melloni, C-399/11; TJUE, sentencia de 26 de febrero de 2013, Åklagaren/Hans Åkerberg Fransson, C-617/10.

28 TJUE, sentencia de 8 de septiembre de 2015, Taricco, C-105/14, y TJUE (Gran Sala), sentencia de 5 de diciembre de 2017, Procedimiento penal contra M.A.S. y M.B., C-42/17. Sobre la «saga Taricco» y en particular el asunto M.A.S, se permita el reenvío a: FAGGiani (2018).

29 Por lo tanto, hasta el 30 de noviembre de 2014 siguió aplicándose el antiguo art. 35 TUE, según el cual la competencia del TJ en el ámbito de la cooperación judicial en materia penal estaba condicionada a una declaración de aceptación de parte de cada Estado miembro. Ni el Reino Unido ni Irlanda efectuaron dicha declaración. 
oportuno subrayar que el Reino Unido, mientras no se salga de forma definitiva de la UE, continuará a disfrutar junto a Irlanda y Dinamarca del régimen de opt-out/opt-in en el ámbito del ELSJ ${ }^{30}$. Esto significa que de momento todas las medidas de cooperación judicial en materia penal a las que el Reino Unido se ha adherido, con la inclusión de la ODE, ${ }^{31}$ deben seguir ejecutándose, igual que antes $^{32}$. En cambio, no se puede todavía prever cuál será el escenario cuando se haga efectivo el Brexit. A falta di un acuerdo de retirada, tras el rechazo del texto negociado entre la UE y Londres por el Parlamento británico el pasado 15 de enero de 2019, la salida se debería concretar el próximo 29 de marzo, es decir dos años después de la notificación al Consejo Europeo (art. 50, ap. 2, TUE). Se trata de una situación de fuerte incertidumbre. Como afirma el Abogado General «Todo lo demás puede estar escrito en las estrellas. Y no parece que esas estrellas sean las de la bandera europea» ${ }^{33}$.

30 Inicialmente, atendiendo al art. 19, apartados 4 y 5, del Protocolo n. 36, el Reino Unido ejerció el derecho a no participar en los actos de la UE adoptados en el ámbito de la cooperación judicial en materia penal antes de la entrada en vigor del Tratado de Lisboa (documento del Consejo 12750/13, «Notificación del Reino Unido con arreglo al art. 10, ap. 4, del Protocolo n. 36 del TUE y del TFUE», de 26 de julio de 2013). Sin embargo, en un segundo momento, decidió adherirse a 35 medidas (documento del Consejo 15398/14, «Notificación del Reino Unido con arreglo al art. 10, ap. 5, del Protocolo n. 36 de los Tratados de la Unión», de 27 de noviembre de 2014, y Decisión 2014/857/UE del Consejo, de 1 de diciembre de 2014, relativa a la notificación del Reino Unido de Gran Bretaña e Irlanda del Norte de su deseo de participar en algunas de las disposiciones del acervo de Schengen contenidas en actos de la Unión en el ámbito de la cooperación policial y judicial en materia penal, y por la que se modifican las Decisiones 2000/365/CE y 2004/926/CE (DO 2014 L 345, p. 1). Al respecto, es interesante observar que entre las medidas que este País no ha incorporado se encuentran, por ejemplo, la Directiva 2013/48/UE sobre derecho de acceso a un abogado y las demás medidas en materia procesal del segundo paquete. Sobre el opt-ing del Reino Unido, se reenvía a: Mitsilegas, Carrera, Eisele (2014: pp. 7, 16 у 21$)$.

31 La Decisión marco 584/2002 ha sido transpuesta en el Reino Unido por el Extradition Act 2003.

32 En estos términos se expresa también el Abogado General Sr. Maciej Szpunar en las conclusiones presentadas el 7 de agosto de 2018, Minister for Justice and Equality c. R.O., asunto C-327/18 PPU.

33 Ibídem, ap. 79. Según el Abogado General «El Brexit constituye terra incognita desde el punto de vista del Derecho de la Unión. Se sabe poco acerca de los acuerdos que deberán establecerse entre la Unión y el Reino Unido después del 29 de marzo de 2019, ya sea en general o en relación con el sistema de la ODE en particular. Lo que es seguro es que, tras la retirada de la Unión, la marea bajará en algún momento. El Derecho de la Unión descenderá río abajo y se evacuará a través los estuarios». Sobre los efectos del Brexit en el ámbito de la cooperación judicial en materia penal vid. Acale Sánchez (2018); Jimeno Bulnes (2017); Mitsilegas (2017); WeYEMBERGH (2017). 


\section{VI.Profundización y variabilidad en la Cooperación Judicial: Los frenos de emergencia y la cooperación reforzada}

A pesar de su carácter innovador y de su importancia en el proceso de construcción europea, en el Tratado de Lisboa siguen permaneciendo algunos aspectos que parecen contradictorios y controvertidos, los cuales podrían crear obstáculos, hasta llegar, en algunos casos, a paralizar la creación de un espacio de justicia armonizado. Entre los elementos calificados por la doctrina de concesiones o elementos de fractura y fragmentación es preciso destacar: el mecanismo de los «frenos de emergencia», la cooperación reforzada y el «régimen de optout/opt-in» reservado al Reino Unido, Irlanda y Dinamarca. Tales elementos, sin embargo, han sido necesarios para dar más flexibilidad al sistema y superar las reticencias de algunos Estados a una intervención de la UE en ámbitos por tradición reservados a la soberanía nacional, como la justicia o la política en materia de inmigración.

El Tratado de Lisboa introduce en los arts. 82.3 y 83.3 TFUE el mecanismo de los «frenos de emergencia» («emergency breake»), que se encuentra relacionado estrictamente con el mecanismo de la cooperación reforzada. Cuando un miembro del Consejo considere que un proyecto de directiva con el que se pretende aproximar las legislaciones penales sustantivas o procesales afecte a aspectos fundamentales de su sistema de justicia penal -que, sin embargo, el Tratado de Lisboa no se preocupa por especificar-, podrá solicitar que dicho asunto se remita al Consejo Europeo, que procederá a suspender el procedimiento legislativo ordinario y lo podrá reactivar, previa deliberación y en el caso de que se alcance el consenso, en el plazo de cuatro meses de dicha suspensión, devolviendo el proyecto al Consejo. Este último podrá reanudar su tramitación, teniendo en cuenta las observaciones formuladas, o poner fin al procedimiento, pidiendo, si procede, una nueva propuesta de la Comisión. El mecanismo de los «frenos de emergencia» no solo puede equilibrar, en determinadas circunstancias, la introducción del voto por mayoría cualificada, permitiendo proteger los intereses particulares de los Estados miembros, sino que, mediante la ampliación del procedimiento legislativo ordinario y la posibilidad de revisar los proyectos 
legislativos, consigue desbloquear el veto de algunos Estados y llegar a la adopción de actos normativos de particular relevancia. Todo ello contribuye sin duda a evitar la parálisis del sistema.

Además, dicho mecanismo se ve reforzado por la posibilidad de que, si no hubiese acuerdo dentro de ese mismo plazo y previa comunicación al Parlamento Europeo, al Consejo y a la Comisión, se establezca una cooperación reforzada entre al menos nueve Estados miembros (arts. 20.2 TUE y 329.1 TFUE). La cooperación reforzada estará abierta a todos los Estados miembros en cualquier momento, siempre y cuando se respeten las posibles condiciones de participación establecidas en la decisión de autorización. Aunque da vida a una Europa a «dos velocidades» y caracterizada por una «integración diferenciada», en determinadas circunstancias, puede resultar de gran importancia e incluso necesaria para impulsar la armonización progresiva de sectores específicos. Cuando un grupo de Estados miembros decide instituir una cooperación reforzada, lo hace también en el intento de que los demás Estados miembros progresivamente se adhieran, conformándose a tal marco normativo.

La primera aplicación de este instrumento al ámbito penal ha conseguido impulsar la adopción del Reglamento (UE) 2017/1939 del Consejo de 12 de octubre de 2017 por el que se establece una cooperación reforzada para la creación de la Fiscalía Europea ${ }^{34}$. El 3 de abril de 2017, ante la falta de unanimidad en el Consejo en relación con la Propuesta de Reglamento relativo a la creación de la Fiscalía Europea, en el seno de la UE se activó dicho procedimiento, que alcanzó el 8 de junio de 2017 el apoyo de veinte Estados miembros ${ }^{35}$. Los demás Estados miembros pueden adherirse en cualquier momento tras la adopción del Reglamento.

La Fiscalía Europea, que atendiendo a lo dispuesto en el art. 86 TFUE debe instituirse a partir de Eurojust, tendrá la función de «investigar, procesar

34 DOUE L 283/1, 31.10.2017. Obsérvese que la Fiscalía Europea, atendiendo al art. 86 TFUE, tenía que instituirse por reglamento y no por directiva. El reglamento es un acto normativo obligatorio en todos sus elementos y directamente aplicable en los Estados Miembros de la UE.

35 Austria, Bélgica, Bulgaria, Croacia, Chipre, Chequia, Estonia, Finlandia, Francia, Alemania, Grecia, Italia, Letonia, Lituania, Luxemburgo, Portugal, Rumanía, Eslovaquia, España y Eslovenia. 
y llevar a juicio a los autores de los delitos contra los intereses financieros de la Unión con arreglo a la Directiva (UE) 2017/1371 del Parlamento Europeo y del Consejo ${ }^{36}$, así como los delitos que están indisociablemente vinculados con ellos». Tales competencias podrán ser ampliadas a otros delitos graves de dimensión transfronteriza previa decisión unánime del Consejo Europeo.

El modelo europeo de cooperación judicial en materia penal ha ido adquiriendo forma y contenido en el tiempo, desde la experiencia de los convenios internacionales de armonización en el ámbito del Consejo de Europa, pasando por la fase de la cooperación intergubernamental, que llevó a la adopción del Convenio de Schengen, concebido como el laboratorio para un modelo de justicia penal europeo. Dicho modelo empezó a tener concreción tras la adopción del Tratado de Maastricht y de ahí se transformó progresivamente en una realidad supranacional hasta su definitiva «comunitarización» en el Tratado de Lisboa. Este último, mediante la supresión formal de los pilares comunitarios, ha supuesto un avance muy importante, al haber dotado finalmente a la UE de una competencia expresa en el ámbito procesal penal, que la legítima a establecer normas mínimas comunes en materia penal (sustantiva y procesal) bajo la forma de directiva.

La adopción, aunque a pequeños pasos, de todas estas medidas, a pesar de las contradicciones y de los límites que caracterizan a este sistema, representa la señal de que la UE se ha dado finalmente cuenta de la necesidad y de la oportunidad de llevar a cabo una acción legislativa desde un nivel de tutela supranacional, trascendente a los ordenamientos jurídicos nacionales en tiempos rápidos, mediante el desarrollo de mecanismos de cooperación judicial eficientes, el refuerzo del reconocimiento mutuo de las sentencias y resoluciones judiciales y la aproximación de las legislaciones en el ámbito europeo. Se trata de elementos que tras la entrada en vigor del Tratado de Lisboa han adquirido un valor «materialmente constitucional».

36 DOUE, L 198/29, 28.7.2017. 


\section{Bibliografía}

Acale, M. (2018). «Efectos del "Brexit" en el ámbito de la política criminal de la Unión Europea y de Reino Unido». Revista de Derecho Comunitario Europeo, (59), pp. 97-142. DOI: $10.18042 / \mathrm{cepc} / \mathrm{rdce} .59 .03$

Adam, R. (1998). «La cooperazione in materia di giustizia e affari interni tra comunitarizzazione e metodo intergovernativo». Dir. Un. Eur, 3 (2-3), pp. 481-509.

Alonso, R. (2007). «Justicia constitucional y Unión Europea». En Revenga, M., Pajeres, E., Rodríguez-Drincourt, J. (Coords.), 50 años de Corte Constitucional italiana, 25 años de Tribunal Constitucional español. Madrid: Ministerio de Justicia, Secretaría General Técnica, pp. 331-358.

Aprile, E. y Spiezia, F. (2009). Cooperazione giudiziaria penale nell'Unione europea prima e dopo il Trattato di Lisbona. Milano: Wolters Kluwer.

Arangüena, C. (2016). «Nuevos avances en la armonización de garantías procesales en la Unión Europea». En González, M. (Coord.), Cooperación judicial penal en la Unión Europea. Valencia: Tirant lo Blanch, pp. 267-315.

Arangüena, C. (2017). «Las garantías procesales de sospechosos e imputados en los procesos penales». En Gutiérrez, A. (Coord.), Los retos del espacio de Libertad, Seguridad y Justicia de la Unión Europea en el año 2016. Madrid: Wolters Kluwer, pp. $1-13$.

Arangüena, C. (Coord.) (2010). Espacio europeo de libertad, seguridad y justicia: últimos avances en cooperación judicial penal. Valladolid: Lex Nova.

Arangüena, C. (Coord.) (2011). Cooperación judicial civil y penal en el nuevo escenario de Lisboa. Granada: Comares.

Arangüena, C. y de Hoyos, M. (Dirs.). (2018). Garantías Procesales de Investigados y Acusados: Situación Actual en el Ámbito de 
la Unión Europea. España: Tirant lo Blanch.

Bernardi, A. (2004). «Europeizzazione del diritto penale e progetto di costituzione europea». Diritto Penale e Processo, 10(1), pp.

5-12. Recuperado de http://hdl.handle.net/11392/1197762

Bernardi, A. (2004). L'europeizzazione del diritto e della scienza penale. Torino: Giappichelli.

Bernardi, A. (2013). «Interpretazione conforme al diritto UE e costituzionalizzazione dell'Unione europea. Brevi osservazioni di un penalista». Diritto Penale Contemporaneo, (3), pp. 230241. Recuperado de https://www.penalecontemporaneo.it/ upload/1373566722BERNARDI\%202013.pdf

Bilancia, P. (2004). «Lo spazio di libertà, sicurezza e giustizia tra realtà intergovernativa e prospettiva comunitaria». Riv. it. dir. pubbl. com., (2), pp. 345-366.

Calderón, M. e Iglesias, J. (Coords.). (2009). El espacio europeo de libertad, seguridad y justicia: avances y derechos fundamentales en materia procesal. Cizur Menor: Aranzadi.

Chiavario, M. (2005). «Cooperazione giudiziaria e di polizia in materia penale a livello europeo». Riv. it. dir. e proc. pen., (3), pp. 974-990.

Condinanzi, M. (2007). «Fonti del "terzo pilastro" dell’Unione Europea e ruolo della Corte Costituzionale». Il Diritto dell'Unione Europea, (3), pp. 513-539.

De Hoyos, M. (2018). «Algunas dificultades y cuestiones pendientes en la cooperación judicial penal en el ámbito de la Unión Europea relativas a las garantías procesales». En González, M. (Coord.), Integración europea y justicia penal. Valencia: Tirant lo Blanch, pp. 89-124.

De Miguel Zaragoza, J. A. (2004). «Cooperación judicial penal en la Constitución Europea». BIMJ, 58(1975), pp. 3523-3536. Faggiani, V. (2017). Los derechos procesales en el espacio europeo de justicia penal. Técnicas de armonización. Madrid: Aranzadi. Faggiani, V. (2018). «El diálogo jurisdiccional tras la sentencia del 
TJUE M.A.S. y M.B.: entre estándar europeo de protección y tendencias centrípetas». Revista de Derecho Comunitario Europeo, (60), pp. 639-676. DOI: 10.18042/cepc/rdce.60.05 Faggiani, V. (2017). «Le direttive sui diritti processuali. Verso un "modello europeo di giustizia penale"?». Freedom, Security \& Justice, (1), pp. 84-103.

García, N. (2010). «La tutela de las garantías penales tras el Tratado de Lisboa». Revista General de Derecho Penal, (14), pp. 1-25. Gómez-Jara, C. (2004). «Orden de detención europea y Constitución europea: reflexiones sobre su fundamento en el principio de reconocimiento mutuo». La Ley, (4), pp. 1606-1615.

Jimeno, M. (2010). «Las implicaciones del Tratado de Lisboa en la cooperación judicial europea en materia penal». En Arangüena, C. (Dir.), Espacio europeo de libertad, seguridad y justicia: últimos avances en cooperación judicial penal. Valladolid: Lex Nova, pp. 30-70.

Jimeno, M. (2017). «Brexit and the future of European criminal Law - A Spanish perspective». Criminal Law Forum, 28(2), pp. 325-347.

Kostoris, R. (2017). Manuale di procedura penale europea. Milano: Giuffrè.

Lirola, I. (2008). «La cooperación judicial en materia penal en el Tratado de Lisboa: ¿un posible proceso de comunitarización y consolidación a costa de posibles frenos y fragmentaciones?». Revista General de Derecho Europeo, (16), pp. 1-25.

Mitsilegas, V. (2017). «Cross-border criminal cooperation after Brexit». En Dougan, M. (Ed.), The UK after Brexit. Legal and policy challenges. Cambridge, Amberes, Portland: Intersentia, pp. 203-221.

Mitsilegas, V., Carrera, S. y Eisele, K. (2014). «The End of the Transitional Period for Police and Criminal Justice Measures Adopted before the Lisbon Treaty: Who monitors trust in the European Criminal Justice area?». CEPS Papers in Liberty 
and Security in Europe, (74), pp. 1-45. Recuperado de https:// www.ceps.eu/publications/end-transitional-period-police-andcriminal-justice-measures-adopted-lisbon-treaty-who

Montaldo, S. (2015). I limiti della cooperazione in materia penale nell'Unione Europea. Napoli: Editoriale Scientifica.

Munari, F. y Amalfitano, C. (2007). «Il “terzo pilastro” dell’Unione: problematiche istituzionali, sviluppi giurisprudenziali, prospettive». Dir. Un. eur., (4), pp. 773-809.

Sánchez, A. (2007). «La Euro-Orden, el principio de doble incriminación y la garantía de los derechos fundamentales». Revista Electrónica de Estudios Internacionales, (14), pp. $1-56$.

Sarmiento, D. (2004). Poder judicial e integración europea: la construcción de un modelo jurisdiccional para la Unión. Madrid: Civitas.

Wasmeier, M. y Thwaites, N. (2004). «The battle of the pillars: does the European Community have the power to approximate national criminal laws?». European Law Review, 29(5), pp. 613-635.

Weyembergh, A. (2017). «Consequences of Brexit for European criminal law». New Journal of European Criminal Law, 8(3), pp. 284-299.

Cómo citar este artículo: Faggiani, V. (2019). El modelo europeo de cooperación judicial en materia penal tras el Tratado de Lisboa. Derecho Global. Estudios sobre Derecho y Justicia, 4(11), pp. 17-44. DOI:10.32870/dgedj.v0i11.217 